\title{
Modeling of Chloride Distribution in Cement-Based Materials with Neumann Boundary Condition
}

\author{
Qi Meng, ${ }^{1}$ Yan Zhang $\mathbb{D}^{1},{ }^{1}$ Chun-jin Lin, ${ }^{2}$ Lin-hua Jiang, ${ }^{1}$ and Da Chen $\mathbb{D}^{3}$ \\ ${ }^{1}$ College of Mechanics and Materials, Hohai University, Nanjing, China \\ ${ }^{2}$ College of Sciences, Hohai University, Nanjing, China \\ ${ }^{3}$ College of Harbor, Coastal and Offshore Engineering, Hohai University, Nanjing, China \\ Correspondence should be addressed to Yan Zhang; yan.zhang@hhu.edu.cn and Da Chen; chenda@hhu.edu.cn
}

Received 10 April 2018; Revised 10 July 2018; Accepted 29 July 2018; Published 23 August 2018

Academic Editor: Jun Liu

Copyright ( 2018 Qi Meng et al. This is an open access article distributed under the Creative Commons Attribution License, which permits unrestricted use, distribution, and reproduction in any medium, provided the original work is properly cited.

\begin{abstract}
The nonstable transport of chloride in cement-based materials, including diffusion, convection, and chloride binding, is described as a general form of Fick's law. Inspired by the heat transport of concrete, the second boundary condition called the Neumann boundary condition is considered in the chloride transport of concrete. The theoretical deduction of one-dimensional chloride distribution with the Neumann boundary condition is performed, while a virtual boundary is introduced to carry out the approximate treatment. Finally, the comparison between the general Dirichlet boundary condition and the present Neumann boundary condition and the influence of the thickness of the virtual boundary as well as the influence of the water-cement ratio $(\mathrm{w} / \mathrm{c})$ are discussed.
\end{abstract}

\section{Introduction}

It is well known that concrete structures exposed to the chloride environment, e.g., seawater and deicing salts, might be seriously damaged due to the chloride-induced corrosion of internal steel. With the continuous penetration of chloride, the $\mathrm{pH}$ value around steel is decreased, while the chloride value is increased. When chloride concentration reaches some given level called the threshold value, steel would be corroded [1]. Therefore, the determination of the transport of chloride [2-4] and threshold value [5-8] as well as improvement of chloride resistance [9-11] is the hot topic for decades.

It is reasonable to consider that the determination of the transport of chloride is the basic and most important research to promote theories from the experimental results $[3,12]$ and develop life prediction models of concrete structures [13-16]. The diffusion caused by the chemical potential gradient [2] and the convection caused by the collective movement of groups or aggregates of molecules within fluids [17] are two main mechanisms of chloride transport in general conditions. Theoretically, they follow
Fick's law [4] and Darcy's law [18, 19], respectively. In fact, the chloride transport, especially nonstable transport, is a complicated process while one cannot distinguish clearly their two mechanisms from the chloride distribution [20-22]. Furthermore, chemical/physical chloride binding by the hydration products reduces the free chloride concentration and retards the penetration of chloride to the level of the steel [23-25]. The discussion between free chloride and total chloride that which one can be responsible for the corrosion initiation is still existing [2629]. Thus, free chloride is more used to evaluate the corrosion risk of reinforce concrete, while total chloride is collected and analyzed as a reference. Experimental studies have been performed by different researchers, and the main conclusions are as follows [30-32]: (i) it is hard to determine exactly the chloride concentration at depths smaller than about $5 \mathrm{~mm}$, (ii) the distributions of total chloride and free chloride have the similar tendency, and (iii) with the increase of depth, the chloride concentration decreases rapidly while its distribution follows the partial differential equation as $\partial C / \partial t=\alpha \nabla^{2} C$. Figure 1 shows the general chloride concentration profiles. 


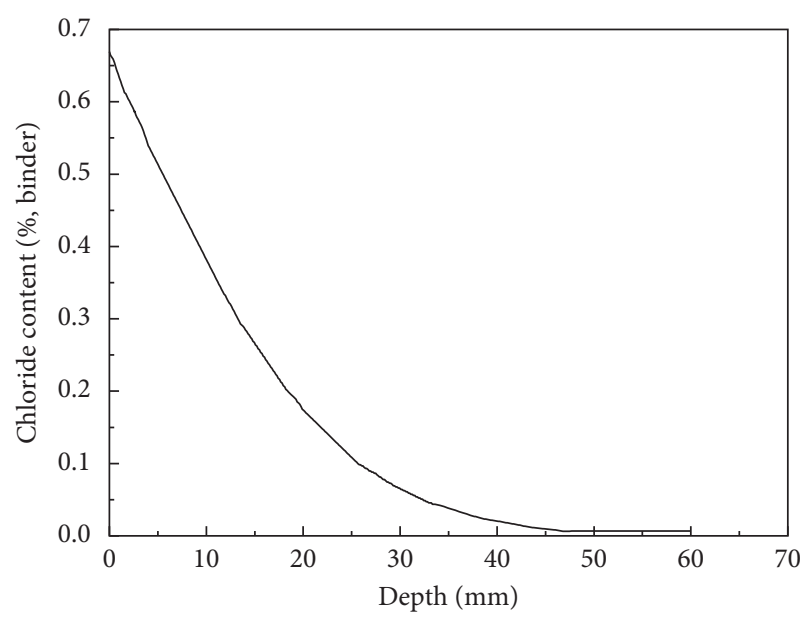

FIGURE 1: General chloride concentration profiles [33].

It is well known that the nonstable diffusion follows Fick's second law with $\partial C / \partial t=D \nabla^{2} C$, where $D$ is the diffusion coefficient. Note that the actual transport of chloride needs to take into account several different mechanisms and the coupling between them; it is unsuitable to describe its transport character as the diffusion coefficient. The actual transport of chloride is normally defined as $\partial C / \partial t=D_{\text {app }} \nabla^{2} C$, where $D_{\text {app }}$ is the apparent diffusion coefficient generally obtained by the curve fitting of free chloride concentration with Fick's second law [12, 33-35]. Also, a series of models based on this basic law have been developed to take into account the multi-ionic effect [36], temperature [37, 38], stress [39-41], electrical field [42], curing age $[14,43,44]$, etc. And the relevant development is based on the mathematical calibration of various forms of partial differential equation with the first boundary condition called the Dirichlet condition. With the Dirichlet boundary condition, the surface chloride concentration of concrete is prescribed as a given value, e.g., chloride concentration of the external chloride environment. However, the Dirichlet condition might not be accurate especially in the zone of severe changes. In this type of zone, the distribution of chloride concentration varies drastically that one cannot determine the exact value. Thus, the surface chloride concentration of concrete is not equal to chloride concentration of the external chloride environment [31]. In fact, the evolution of chloride concentration is controlled by the flux of chloride ions across the surface, while it is proportional to the chloride concentration difference between the surface and the surrounding medium. This boundary condition is called as the Neumann boundary condition, and it is widely applied to the thermal stress and temperature analysis of mass concrete $[45,46]$. Considering the similar conditions that temperature/chloride concentration is violently changed at the surface zone of concrete, it is reasonable to assume that the boundary condition of chloride transport might be considered as the Neumann boundary condition as better.

The present research is organized as follows: first, the differential equation of nonstable transport of chloride with two different boundary conditions is summarized. Then, we focus on the one-dimensional case with the Neumann boundary condition, and its exact solution with the constant apparent diffusion coefficient is deduced by the mathematical method. Considering the disadvantage of resolving its exact solution, a virtual boundary is introduced to simplify the approximate deduction. According to relevant experimental results, the comparison between the general Dirichlet boundary condition and the present Neumann boundary condition and the influence of the thickness of the virtual boundary as well as the influence of the water-cement ratio $(\mathrm{w} / \mathrm{c})$ are discussed.

\section{Description of Chloride Transport with Two Boundary Conditions}

2.1. General Expression. As mentioned above, the nonstable chloride transport can be described as Fick's second law and one-dimensional expression is as follows:

$$
\frac{\partial C_{\mathrm{f}}(x, t)}{\partial t}=D_{\mathrm{app}} \frac{\partial^{2} C_{\mathrm{f}}(x, t)}{\partial x^{2}}
$$

where $D_{\text {app }}$ is the apparent diffusion coefficient $\left(\mathrm{m}^{2} / \mathrm{s}\right), t$ is the exposure time $(\mathrm{s})$, and $C_{\mathrm{f}}(x, t)$ is the free chloride concentration at depth $x(\mathrm{~m})$ after time $t\left(\% / \mathrm{m}^{3}\right) . D_{\text {app }}$ can be determined as a constant or a variable considering the multi-ionic effect, temperature, stress, electrical field, curing age, etc.

And also, the initial chloride concentration of the structure is given as follows:

$$
C(x, 0)=C_{0} \text {. }
$$

This paper focuses on the influence of different boundary conditions so that one simplified example with $D_{\text {app }}$ as a constant is performed later.

2.2. First Boundary Condition. The first kind of boundary condition is called the Dirichlet boundary condition. It is the prescribed chloride concentration given as follows:

$$
C(0, t)=C_{s},
$$

where $C_{\mathrm{s}}$ is the surface chloride concentration.

For the ideal concrete of one semi-infinite medium, the exact solution of Equation (1) with the Dirichlet boundary condition can be derived as an error function solution [47]:

$$
\left.C(x, t)=C_{0}+C_{\mathrm{s}}-C_{0}\right)\left[1-\operatorname{erf}\left(\frac{x}{2 \sqrt{D_{\mathrm{app}} t}}\right)\right]
$$

where erf is the error function. $D_{\text {app }}$ and $C_{\mathrm{s}}$ can be achieved using Equation (4) as a constant. This model is widely used to determine chloride distribution in concrete as well.

2.3. Second Boundary Condition. The second boundary condition is called the Neumann boundary condition. In the application of heat transport of concrete, it is prescribed that heat flux across the surface is proportional to the 
concentration difference between the surface and the surrounding medium:

$$
\frac{\partial T}{\partial n}=\frac{T_{\mathrm{a}}-T}{\lambda / \beta},
$$

where $T_{\mathrm{a}}$ is the environment air temperature, $T$ is the surface temperature of concrete, $\lambda$ is the conductivity of concrete, $\beta$ is the surface conductance, and $n$ is the outward normal of the surface.

In this paper, the Neumann boundary condition is extended to the application of chloride transport as follows:

$$
\frac{\partial C}{\partial n}=\frac{C_{s}-C}{\lambda / \beta},
$$

where $C_{\mathrm{s}}$ is the peak value near the boundary instead of the environment chloride concentration, $C$ is the chloride concentration of the boundary, $\lambda$ is the chloride conductivity of concrete, and $\beta$ is the surface chloride conductance. In the application of chloride transport, it is hard to determine $\lambda$ and $\beta$ compared with the case of heat transport.

\subsection{Exact Solution of Chloride Transport with the Second} Boundary Condition. In this study, an ideal infinite concrete plat (Figure 2) is considered while $D_{\text {app }}$ is a constant and thickness is $2 L$. The chloride can penetrate into this concrete from both the left and right sides.

It can be defined as follows:

$$
\begin{aligned}
\frac{\partial C}{\partial t} & =D_{\text {app }} \frac{\partial^{2} C}{\partial x x}, \quad 0<x<L, \quad t>0, \\
C(x, 0) & =C_{0}, \quad 0 \leq x \leq L, \\
-\frac{\partial C}{\partial x}(L, t) & =\frac{C_{\mathrm{s}}-C(L, t)}{\lambda / \beta}, \quad t \geq 0, \\
\frac{\partial C}{\partial x}(L, t) & =\frac{C_{\mathrm{s}}-C(L, t)}{\lambda / \beta}, \quad t \geq 0,
\end{aligned}
$$

where $\quad-(\partial C / \partial x)(L, t)=\left(C_{s}-C(L, t)\right) /(\lambda / \beta) \quad$ and $-(\partial C / \partial x)(L, t)=\left(C_{s}-C(L, t)\right) /(\lambda / \beta)$ describe the chloride diffusion along the negative direction of $x$-axis and positive direction of $x$-axis, respectively, and $t$ is the exposure time.

In order to get the formed solution of Equation (7), firstly we study the following problem defined on $[0, L]$ :

$$
\begin{aligned}
\partial_{t} u & =D_{\mathrm{app}} u_{x x}, \quad 0<x<L, \quad t>0, \\
u(x, 0) & =C_{0}-C_{s}, \quad 0 \leq x \leq L, \\
\frac{\partial u}{\partial x}(0, t) & =0, \quad \frac{\partial u}{\partial x}=-\frac{u(L, t)}{\lambda / \beta} \quad t \geq 0 .
\end{aligned}
$$

We assume that $u(x, 0)$ is of the form $u(x, t)=X(x) T(t)$ with nontrivial functions $X(x)$ and $T(t)$. Inserting it into the homogeneous equation and the homogeneous boundary condition, we get the eigenproblem:

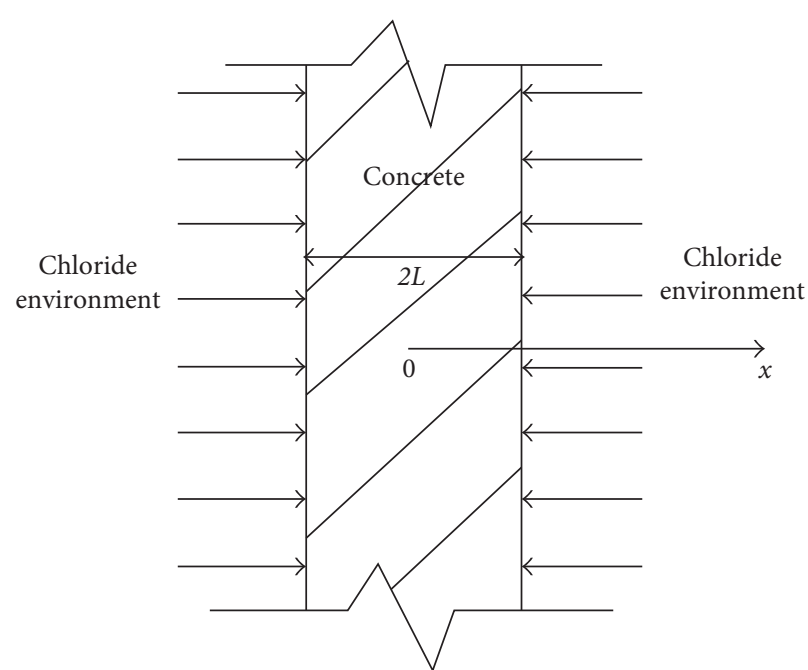

Figure 2: Ideal infinite concrete plat.

$$
\begin{aligned}
X^{\prime \prime}(x)+\lambda X(x) & =0, \quad 0<x<L, \\
X^{\prime}(0) & =0, \quad X^{\prime}(L)+\frac{1}{\lambda / \beta} X(L)=0,
\end{aligned}
$$

and the ordinary differential equation for $T(t)$ :

$$
T^{\prime \prime}+\lambda D_{\text {app }} T(t)=0 .
$$

The parameter $\lambda$ arising in Equation (9) is called the eigenvalue of the problem; the corresponding nontrivial solution $X(x)$ is the so-called eigenfunction. It is well known that the eigenvalues and the eigenfunctions are as follows:

$$
\begin{aligned}
\lambda_{n} & =\left(\frac{\mu_{n}}{L}\right)^{2}, \quad n=1,2, \ldots, \\
X_{n}(x) & =\cos \left(\frac{\mu_{n}}{L} x\right),
\end{aligned}
$$

where $\mu_{n}$ are the positive solution of the equation $x \tan x=L / d$. Then, using the ordinary differential Equation (10), we have

$$
T_{n}(t)=A_{n} e^{-\left(\mu_{n} / L\right)^{2} D_{\text {app }} t} .
$$

Then, the function $u_{n}=X_{n}(x) T_{n}(t)=$ $A_{n} e^{-\left(\mu_{n} / L\right)^{2} D_{\text {app }} t} \cos \left(\left(\mu_{n} x\right) / L\right), \quad(n \geq 1)$, satisfies the homogeneous equation and the homogeneous boundary equation. So does the linear combination of $\mu_{n}$, denoted by $u(0, t)$ :

$$
u(x, t)=\sum_{n=1}^{\infty} A_{n} \cos \left(\frac{\mu_{n} x}{L}\right)=C_{0}-C_{s} .
$$

By the orthogonality of the eigenfunctions, we have

$$
A_{n}=\frac{\left.\left.\left.C_{0}-C_{s}\right) \int_{0}^{L} \cos \mu_{n} x\right) / L\right) d x}{\left.\left.\int_{0}^{L} \cos ^{2} \mu_{n} x\right) / L\right) d x}=\frac{\left.\left.2 C_{0}-C_{s}\right) \sin \mu_{n} L\right)}{\left.\left.\mu_{n}+\sin \mu_{n} L\right) \cos \mu_{n} L\right)} .
$$


Hence, we get the desired form $u(x, t)$ of the problem (8) as follows:

$$
u(x, t)=\sum_{n=1}^{\infty} \frac{\left.\left.2 C_{0}-C_{s}\right) \sin \mu_{n} L\right)}{\left.\left.\mu_{n}+\sin \mu_{n} L\right) \cos \mu_{n} L\right)} \cos \left(\frac{\mu_{n} x}{L}\right) e^{-\left(\mu_{n} / L\right)^{2} D_{\text {app }} t} .
$$

Next, we construct the solution to the one-dimensional general chloride transport Equation (7) as follows:

$$
\begin{aligned}
C(x, t) & = \begin{cases}u(x, t)+C_{s}, & 0 \leq x \leq L, \\
u(-x, t)+C_{s}, & -L \leq x<0,\end{cases} \\
& =\sum_{n=1}^{\infty} \frac{\left.\left.2 C_{0}-C_{s}\right) \sin \mu_{n} L\right)}{\left.\left.\mu_{n}+\sin \mu_{n} L\right) \cos \mu_{n} L\right)} \cos \left(\frac{\mu_{n} x}{L}\right) e^{-\left(\mu_{n} / L\right)^{2} D_{\text {app }} t} .
\end{aligned}
$$

Finally, the exact solution of Equation (7) can be expressed as follows:

$$
\left.C(t, x)=C_{0}+C_{s}-C_{0}\right) \sum_{n=1}^{\infty} A_{n} \cos \frac{\mu_{n} x}{l} e^{-\mu_{n}^{2} \cdot\left(D t / l^{2}\right)},
$$

where $\mu_{n}$ is the infinitely many solutions of $\mu_{n} \tan \mu_{n}=l /(\lambda / \beta), \quad \mu_{1}<\mu_{2}<\cdots<\mu_{n}<\mu_{n+1}<\cdots, \quad$ and $A_{n}=\left(2 \sin \mu_{n}\right) /\left(\mu_{n}+\left(\sin \mu_{n} \cos \mu_{n}\right)\right)$.

In the case of heat transport problems, the number of roots of the characteristic equation is less than 10 to obtain the converging solution. In the present chloride transport problems, the number of roots of the characteristic equation must be selected as $10^{5}$ and even more to ensure the convergence of (17). Furthermore, $\lambda$ and $\beta$ cannot be easily determined as mentioned above. It is considered that direct application of the second boundary condition for chloride transport is unavailable.

\subsection{The Approximate Treatment of the Second Boundary} Condition. When the surface chloride concentration $C$ is changed from $C_{1}$ to $C_{2}$, (6) will be

$$
\begin{aligned}
& \frac{\partial C_{1}}{\partial n}=\tan \phi_{1}=\frac{C_{s}-C_{1}}{\lambda / \beta}, \\
& \frac{\partial C_{2}}{\partial n}=\tan \phi_{2}=\frac{C_{s}-C_{2}}{\lambda / \beta} .
\end{aligned}
$$

As shown in Figure 3(a), the tangents to the chloride curves at the surface will always pass through point $\mathrm{A}$, and the distance between point $\mathrm{A}$ and the surface of concrete is

$$
d=\frac{\lambda}{\beta}
$$

The distribution of chloride with the Neumann boundary condition is presented in Figure 3(b). For the second boundary condition, if a virtual thickness $d=\lambda / \beta$ is introduced to concrete, a virtual boundary is obtained. The chloride concentration on this virtual boundary is equal to $C_{s}$. This means that the introduced virtual boundary satisfies the Dirichlet boundary condition with the prescribed chloride concentration $C_{\mathrm{s}}$ shown in Figure 3(c).

Considering that $d$ is added to the surface, the chloride distribution with the second boundary condition can be rewritten as the general expression of the Dirichlet boundary condition:

$$
\left.C(x, t)=C_{0}+C_{\mathrm{s}}-C_{0}\right)\left[1-\operatorname{erf}\left(\frac{x+d}{2 \sqrt{D_{\mathrm{app}} t}}\right)\right] .
$$

Note that the chloride transport with the Neumann boundary condition is simplified to chloride transport with the Dirichlet boundary condition while an additional parameter $d$ is introduced. Determination of $D_{\text {app }}, C_{s}$, and $d$ can be easily solved.

\section{Experimental Validation}

Diffusion tests and non-steady-state migration tests are carried out to verify the above theoretic results. The apparent diffusion coefficient $\left(D_{\text {app }}\right)$, surface chloride concentration $\left(C_{\mathrm{s}}\right)$, and additional parameter $d$ are obtained from diffusion tests by data fitting. Non-steady-state migration tests are carried out for verifying the variation of the non-steady-state diffusion coefficient $\left(D_{\text {nssm }}\right)$ in hardened concrete. The variation of the non-steady-state diffusion coefficient $\left(D_{\text {nssm }}\right)$ can reflect the changes of the apparent diffusion coefficient $\left(D_{\text {app }}\right)$ indirectly.

3.1. Specimen Preparation. In this study, the samples of mortar were used. Mortar mixtures consisted of Type I Portland cement (according to ASTM 2005b), river sand with a maximum size of $5 \mathrm{~mm}$ and a fineness modulus of 2.90, and tap water. The chemical composition of the cement is given in Table 1, and mixing proportions are given in Table 2 . The mixture was put into $100 \times 100 \times 100 \mathrm{~mm}$ and $\Phi$ $100 \mathrm{~mm} \times 150 \mathrm{~mm}$ molds for diffusion tests and migration tests, respectively. All the samples were stored at $20^{\circ} \mathrm{C}$ and $90 \%$ relative humidity for $24 \mathrm{~h}$ and then were demolded and immersed in $20^{\circ} \mathrm{C}$ water for 7 days; afterwards, the samples were cured in a room at $20^{\circ} \mathrm{C}$ and $90 \%$ relative humidity for 90 days to reduce the time-dependent influence based on the hydration process.

3.2. Diffusion Tests. Cubes with the size of $100 \times$ $100 \times 100 \mathrm{~mm}$ were selected for diffusion tests. Before testing, one side surface of $100 \times 100 \mathrm{~mm}$ was selected as the aggressive surface exposed to the $\mathrm{NaCl}$ solution, while the other five surfaces were coated with epoxy resin to obtain the one-dimensional transport of the chloride in the concrete. Then, all samples were kept immersed in the $2.8 \mathrm{~mol} / \mathrm{L} \mathrm{NaCl}$ solution for 28, 56, and 90 days (Figure 4). The concentration of $\mathrm{NaCl}$ solution was kept constant by sealing the immersion container.

After removing from the $\mathrm{NaCl}$ solution, the first layer of $2 \mathrm{~mm}$ was cut off to avoid the buildup of salt crystals at the surface, and the rest of the samples was grounded into powder every $3 \mathrm{~mm}$ by an electric grinding machine 


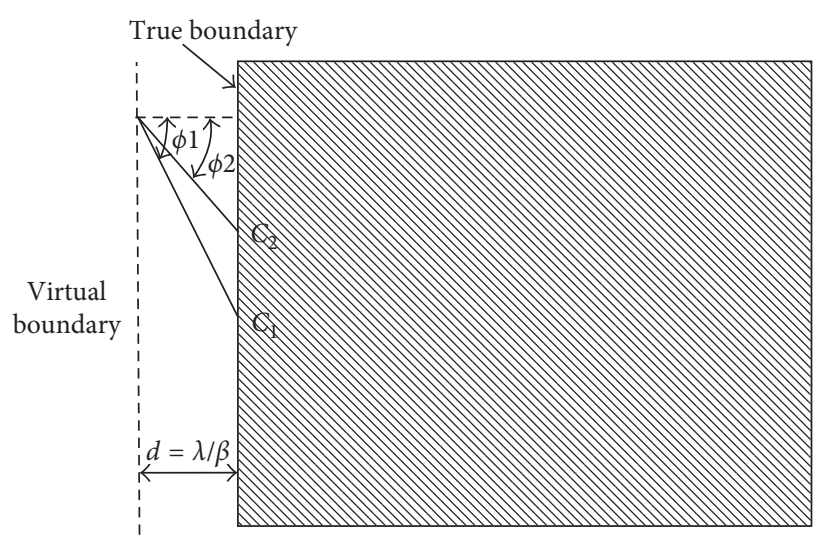

(a)

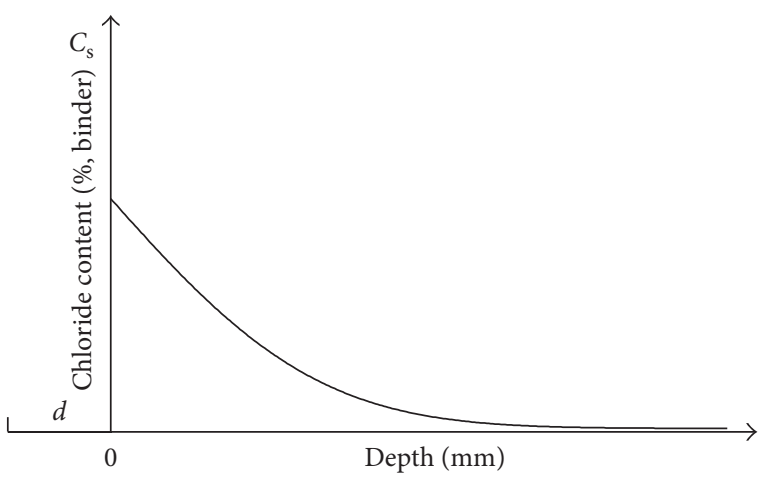

(b)

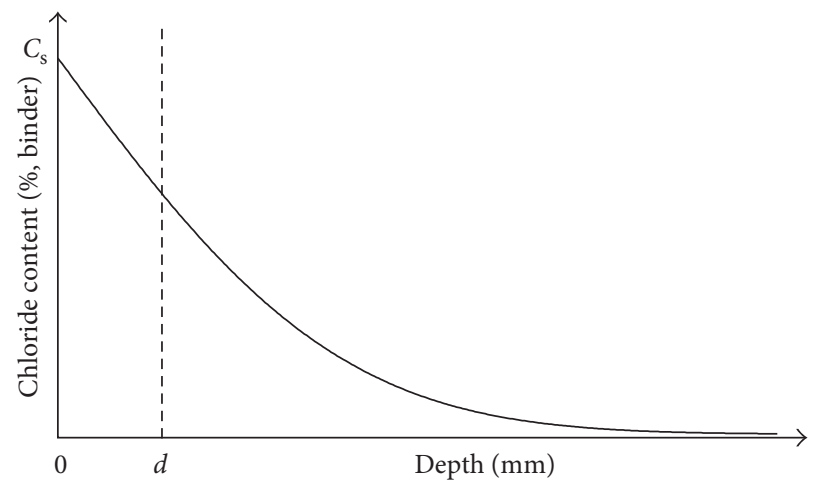

(c)

FIGURE 3: Explanation of the Dirichlet boundary condition and Neumann boundary condition: (a) approximate treatment of the Neumann boundary condition; (b) chloride profile of the Neumann boundary condition; (c) chloride profile of the Dirichlet boundary condition.

TABle 1: Chemical composition of cement.

\begin{tabular}{cccccccccccccc}
\hline & $\mathrm{CaO}$ & $\mathrm{SiO}_{2}$ & $\mathrm{Al}_{2} \mathrm{O}_{3}$ & $\mathrm{Fe}_{2} \mathrm{O}_{3}$ & $\mathrm{MgO}$ & $\mathrm{SO}_{3}$ & $\mathrm{Na}_{2} \mathrm{O}$ & $\mathrm{K}_{2} \mathrm{O}$ & $\mathrm{TiO}_{2}$ & $\mathrm{MnO}_{2}$ & $\mathrm{P}_{2} \mathrm{O}_{5}$ & $\mathrm{LOI}$ \\
\hline Cement & 64.64 & 21.70 & 5.09 & 4.32 & 0.92 & 1.08 & 0.21 & 0.53 & 0.14 & 0.10 & 0.05 & 0.87 \\
\hline
\end{tabular}

(Figure 5) to obtain the chloride concentration profile. All the powder was dried in a stove for $24 \mathrm{~h}$, and chloride was then extracted by distilled water. The free chloride concentration was measured by $\mathrm{AgNO}_{3}$ titration with an automatic potentiometric titrator (Figure 6) related to the mass of the mortar.

3.3. Non-Steady-State Migration Tests. Cylinders with the size of $\Phi 100 \mathrm{~mm} \times 150 \mathrm{~mm}$ were cut into $\Phi$ $100 \mathrm{~mm} \times 50 \mathrm{~mm}$ after demolding. Non-steady-state migration tests were conducted at the age of 7, 14, 28, 56, and 90 days based on NT BUILD 492. $10 \% \mathrm{NaCl}$ solution and $0.3 \mathrm{~mol} / \mathrm{L} \mathrm{NaOH}$ solution were used at the cathode and anode, respectively. An external electrical potential of $30 \mathrm{~V}$ was applied to force chloride ions to migrate into the specimens.

After the tests, the specimens were axially split and $0.1 \mathrm{~mol} / \mathrm{L} \mathrm{AgNO}_{3}$ solution was sprayed on the newly split sections to obtain the chloride penetration depth. The non-steady-state chloride migration coefficient $D_{\text {nssm }}$ can be calculated with the chloride penetration depth, as described in NT BUILD 492, with

$$
D_{\mathrm{nssm}}=\frac{R T}{z F E} \cdot \frac{x_{\mathrm{d}}-\alpha \sqrt{x_{\mathrm{d}}}}{t},
$$

where

$$
\begin{aligned}
& E=\frac{U-2}{L}, \\
& \alpha=2 \sqrt{\frac{R T}{z F E}} \cdot \operatorname{erf}^{-1}\left(1-\frac{2 c_{\mathrm{d}}}{c_{0}}\right) .
\end{aligned}
$$

\section{Results and Discussion}

4.1. Chloride Profiles with Two Boundary Conditions. Experimental values of $D_{\text {app }}$ and $C_{s}$ with two boundary conditions are shown in Table 3. Due to long-period curing and results of non-steady-state migration tests, experimental 
TABLE 2: Mixing proportions of mortar.

\begin{tabular}{lccc}
\hline w/c & Cement $\left(\mathrm{kg} / \mathrm{m}^{3}\right)$ & Sand $\left(\mathrm{kg} / \mathrm{m}^{3}\right)$ & Water $\left(\mathrm{kg} / \mathrm{m}^{3}\right)$ \\
\hline 0.4 & 500 & 1250 & 200 \\
0.45 & 500 & 1250 & 225 \\
0.5 & 500 & 1250 & 250 \\
\hline
\end{tabular}

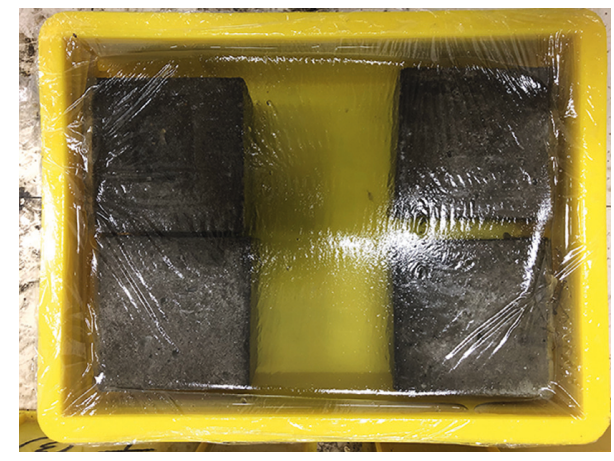

Figure 4: Diffusion tests.

values of $D_{\text {app }}$ and $C_{s}$ change slightly at different exposure times; consequently, the simulation values of $D_{\text {app }}$ and $C_{s}$ are considered stable. As shown in Table 3, it is obvious that both $D_{\text {app }}$ and $C_{\mathrm{s}}$ with the Neumann boundary condition are higher than those with the Dirichlet boundary condition. This means when using the Dirichlet boundary condition, values of $D_{\text {app }}$ and $C_{\mathrm{s}}$ are underestimated and lead to overestimation of service life.

Figure 7 shows the chloride profiles obtained from the diffusion tests. It can be seen that most experimental data are in accordance with the regulation except the data at $3.5 \mathrm{~mm}$. As shown in Figures 7(b) and 7(c), at the depth of $3.5 \mathrm{~mm}$, chloride content with longer days of exposure is higher than that with shorter days of exposure. This is mainly caused by the rapid variation near the surface. Thus, considering that the accuracy and regularity of experimental data at $3.5 \mathrm{~mm}$ are problematic, data at $3.5 \mathrm{~mm}$ are not shown in Figure 8 .

Figure 8 shows the experimental chloride profile with the Dirichlet boundary condition and simulation chloride profile with the Neumann boundary condition, and experimental data are also shown in this figure for comparison. It is obvious that the simulated results are in accordance with the regulation and agree well with the experimental data, which demonstrates that the proposed theoretical model with the Neumann boundary condition is reasonable for predicting the chloride diffusion and service life of cementbased materials.

4.2. Influence of $d$ on Neumann Condition. Values of $d$ with the Neumann condition are also shown in Table 3; values of $d$ fall between $1.5 \mathrm{~mm}$ and $2 \mathrm{~mm}$ and change slightly with the water-cement ratio. This is probably due to the reduction of time-dependent influence, and in this paper, the value of $d$ is only influenced slightly by the water-cement ratio. According to the simulation results calculated by the Intel Visual Fortran, the change of relative error (difference value

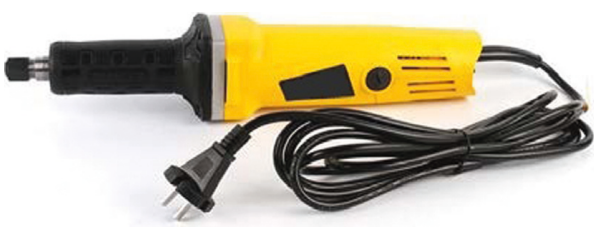

Figure 5: Electric grinding machine.

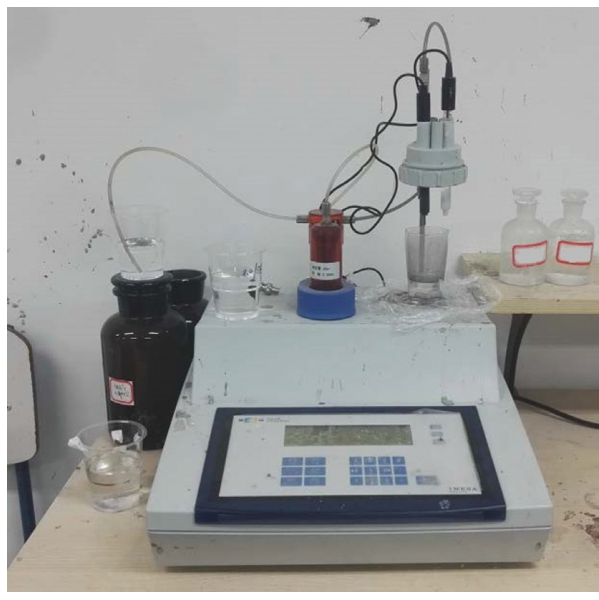

FIgURe 6: Automatic potentiometric titrator.

between simulation data and experimental data) with the width of the virtual boundary $d$ in case of $w / b=0.45$ is shown in Figure 9. As shown in Figure 9, it is obvious that the value of relative error reaches the minimum degree while $d$ is between $1.5 \mathrm{~mm}$ and $2 \mathrm{~mm}$, and the same tendency with $\mathrm{w} / \mathrm{b}=0.4$ and $\mathrm{w} / \mathrm{b}=0.5$ is also obtained. The results imply that the calculated range of $d$ provides an important reference for further study.

4.3. Variation of $D_{n s s m}$ with Curing Age. Variation of $D_{\text {nssm }}$ with curing age is shown in Figure 10; it can be seen that the value of $D_{\text {nssm }}$ changes violently before the curing age of 28 days and then remains almost stable between the curing age of 56 and 90 days. It can be explained that the hydration reaction reduces with the curing age; thus, the value of $D_{\text {nssm }}$ tends to be stable, which indirectly proves that $D_{\text {app }}$ is almost stable at the age of 90 days. In our study, samples were cured for 90 days, and then we perform the diffusion tests. Therefore, the example with $D_{\text {app }}$ as a constant can be considered available.

4.4. Influence of Water-Cement Ratio (w/c). In this study, experimental study is based on three water-cement ratios. As shown in Table 3, with the increase of water-cement ratio, values of $D_{\text {app }}$ and $C_{s}$ increase. This is caused by the higher porosity with the higher water-cement ratio. However, the value of $d$ changed slightly with the water-cement ratio, which implies that $d$ is influenced insignificantly by the water-cement ratio. 
TABLe 3: Values of $D_{\text {app }}, C_{s}$, and $d$ with two boundary conditions.

\begin{tabular}{|c|c|c|c|c|c|c|}
\hline \multirow[b]{2}{*}{$\mathrm{w} / \mathrm{b}$} & \multicolumn{2}{|c|}{$D_{\text {app }}\left(\times 10^{12} \mathrm{~m}^{2} / \mathrm{s}\right)$} & \multicolumn{2}{|c|}{$C_{\mathrm{s}}(\%$, binder $)$} & \multicolumn{2}{|c|}{$d(\mathrm{~mm})$} \\
\hline & $\begin{array}{l}\text { Dirichlet boundary } \\
\text { condition }\end{array}$ & $\begin{array}{c}\text { Neumann boundary } \\
\text { condition }\end{array}$ & $\begin{array}{c}\text { Dirichlet boundary } \\
\text { condition }\end{array}$ & $\begin{array}{c}\text { Neumann boundary } \\
\text { condition }\end{array}$ & $\begin{array}{c}\text { Dirichlet boundary } \\
\text { condition }\end{array}$ & $\begin{array}{c}\text { Neumann boundary } \\
\text { condition }\end{array}$ \\
\hline 0.4 & 10 & 12.5 & 1.1 & 1.25 & & 1.875 \\
\hline 0.45 & 11.3 & 13.8 & 1.175 & 1.25 & & 1.6 \\
\hline 0.5 & 12.5 & 15 & 1.25 & 1.5 & & 1.875 \\
\hline
\end{tabular}

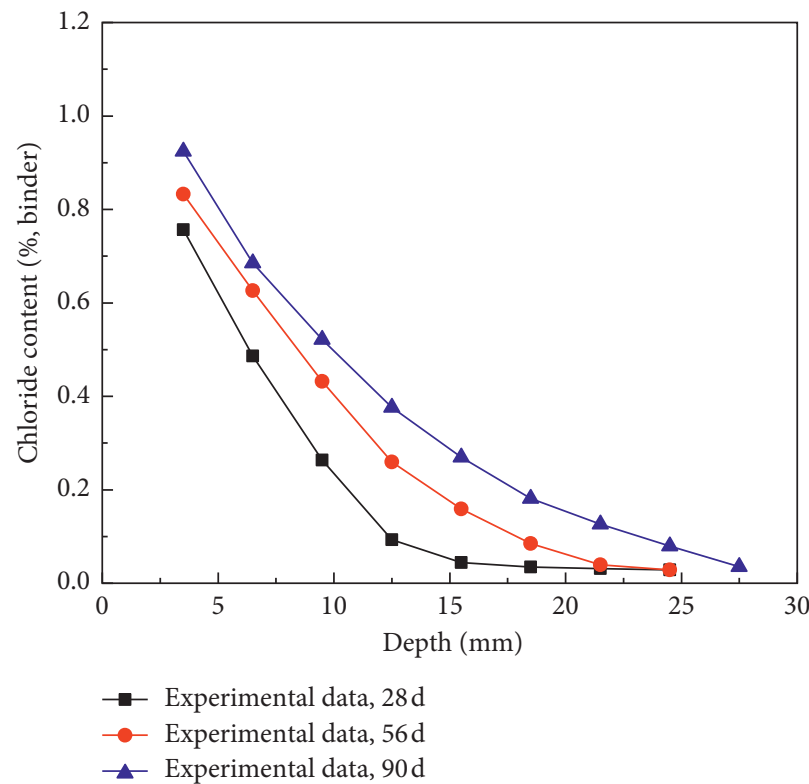

(a)

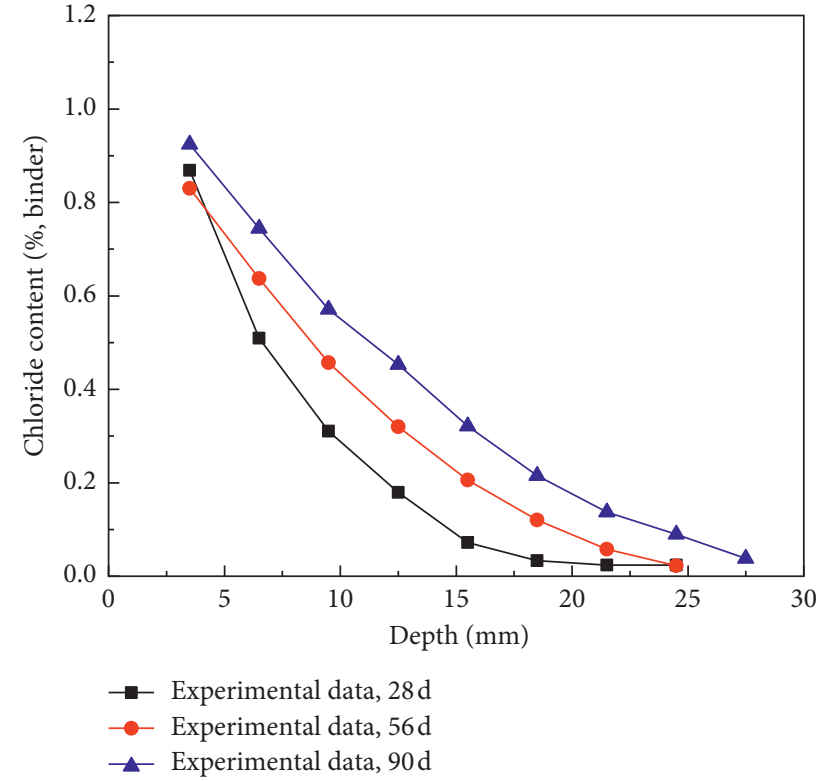

(b)

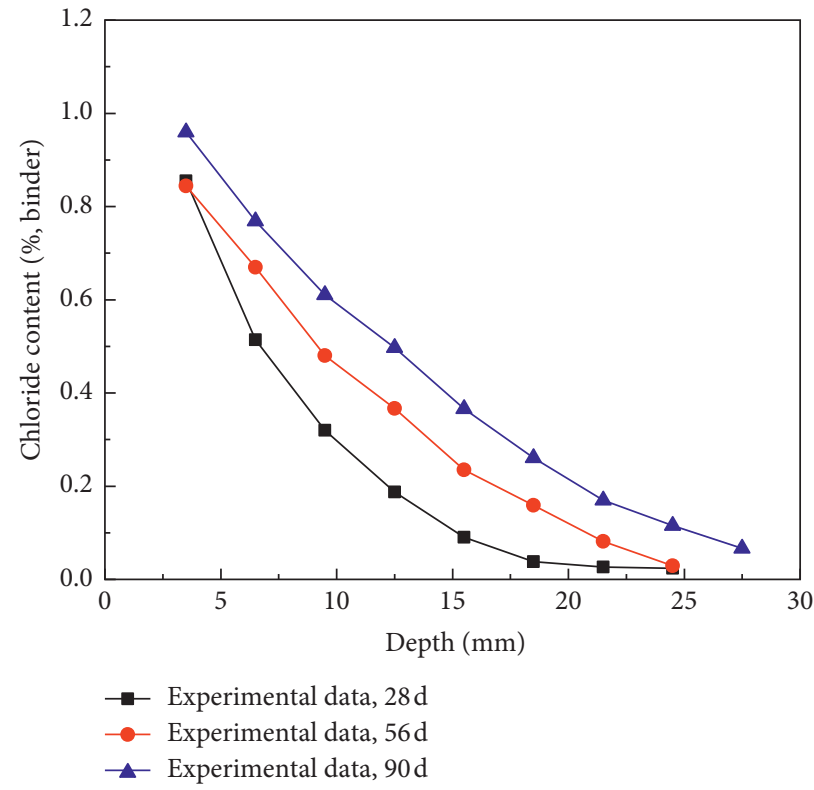

(c)

Figure 7: Chloride profiles obtained from the diffusion tests: (a) w/b $=0.4 ;(b) w / c=0.45 ;(c) w / b=0.5$.

4.5. Long-Term Prediction. Prediction of the chloride profile at the exposure time of 5 years and 10 years based on the tradition model with the Dirichlet boundary condition and the proposed model with the Neumann boundary condition is shown in Figure 11. In the process of prediction, the curing age is still assumed over 90 days so that the value of 


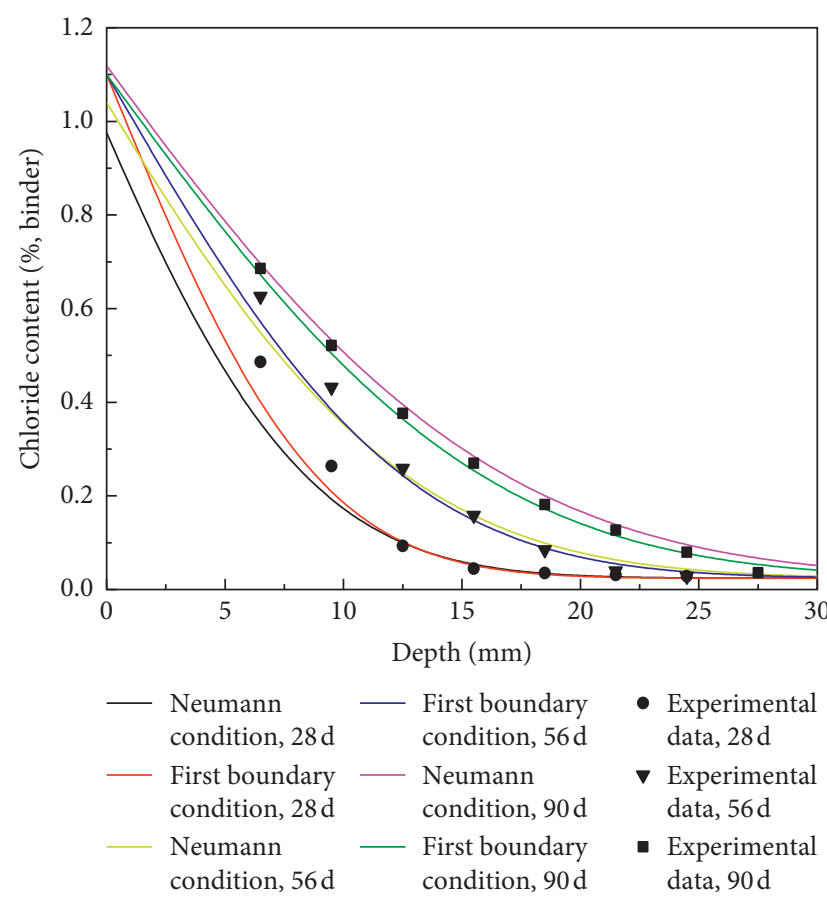

(a)

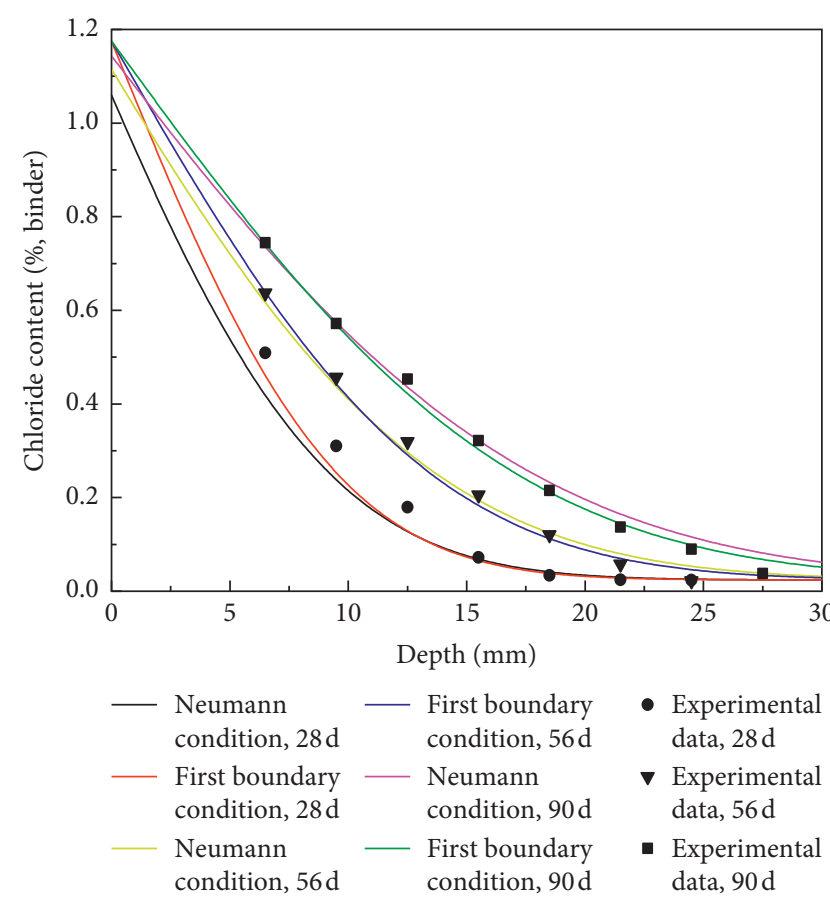

(b)

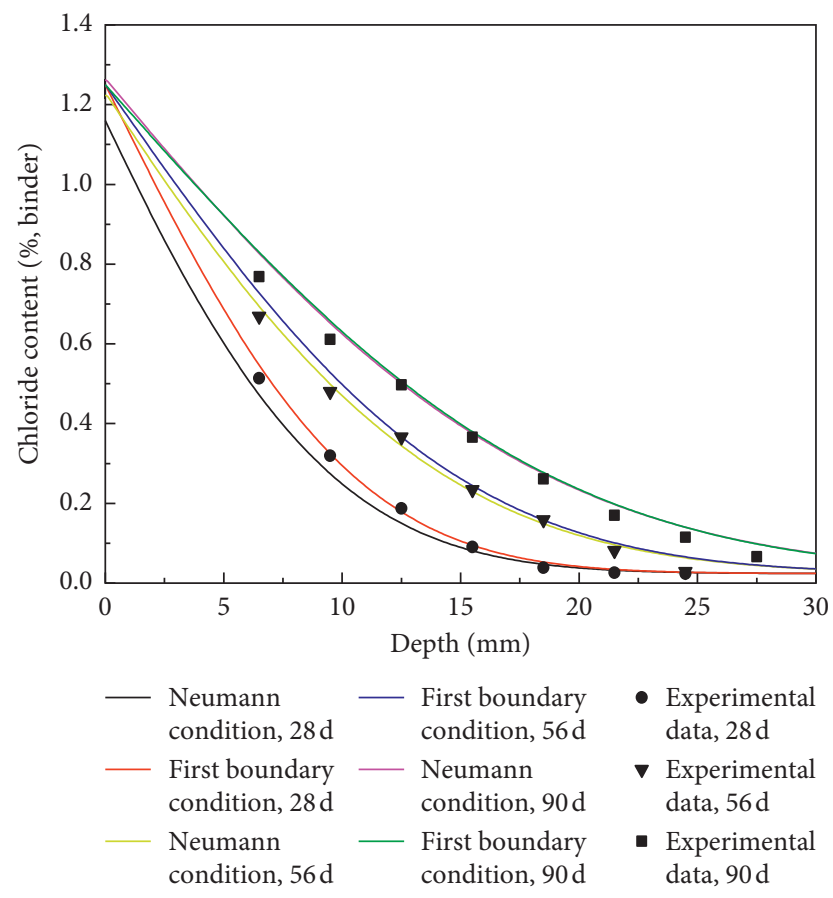

(c)

Figure 8: Chloride profile over time obtained from experimental data and model in the present study: (a) w/b =0.4; $(b)$ w/c $=0.45 ;(c)$ $\mathrm{w} / \mathrm{b}=0.5$.

$D_{\text {app }}$ is considered constant. As shown in Figure 11, it is obvious that, at the same depth, the chloride content obtained from the proposed model is higher, to achieve the same content like $0.1 \%$. At 5 years, the penetration depths of the proposed model and tradition model are $114 \mathrm{~mm}$ and $101 \mathrm{~mm}$, respectively, and at 10 years, the penetration depths are $162 \mathrm{~mm}$ and $143 \mathrm{~mm}$, respectively. The prediction of the proposed model is $13 \%$ higher at both 5 years and 10 years. Considering that the chloride content is underestimated and the service life is overestimated by the tradition model, the present model might be better applied in the case of longterm prediction. 


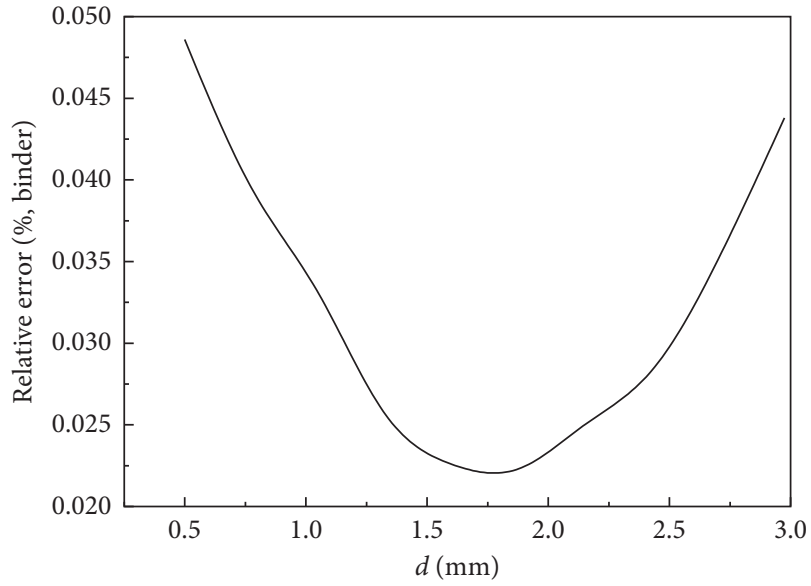

FIgURE 9: Variation of relative error with the width of the virtual boundary.

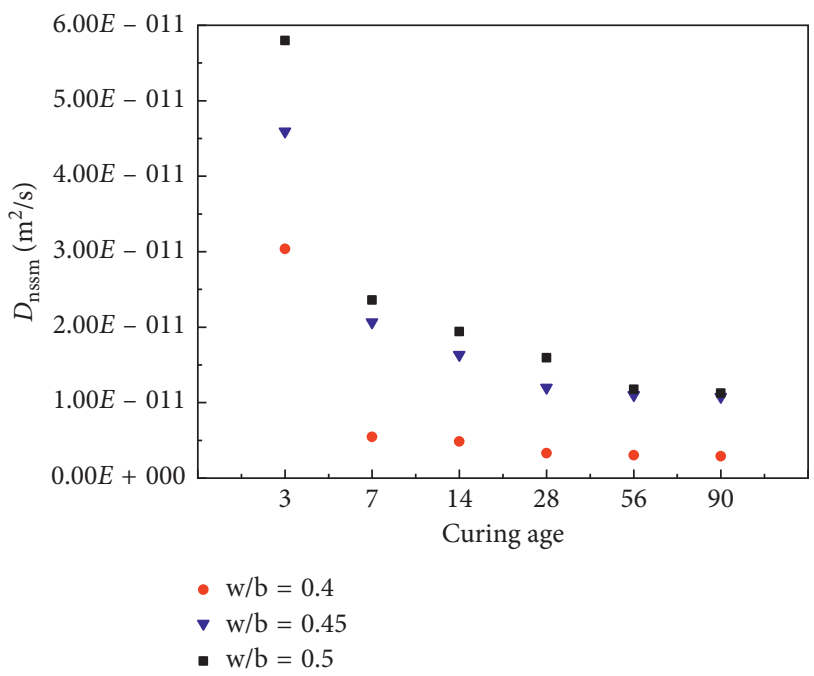

FIgURE 10: Variation of $D_{\text {nssm }}$ with curing age.

\section{Conclusions}

By investigating the theoretical model and experimental data with two boundary conditions, the following conclusions are made:

(1) Due to a complex mechanism, the chloride concentration decreases rapidly with the increasing depth. Considering the violent evolution in this zone, the chloride distribution model in cement-based materials with the Neumann boundary condition was proposed.

(2) One-dimensional case with the Neumann boundary condition and its exact solution with the constant apparent diffusion coefficient $\left(D_{\text {app }}\right)$ are deduced by the mathematical method, and a virtual boundary $d$ was introduced to simplify the approximate

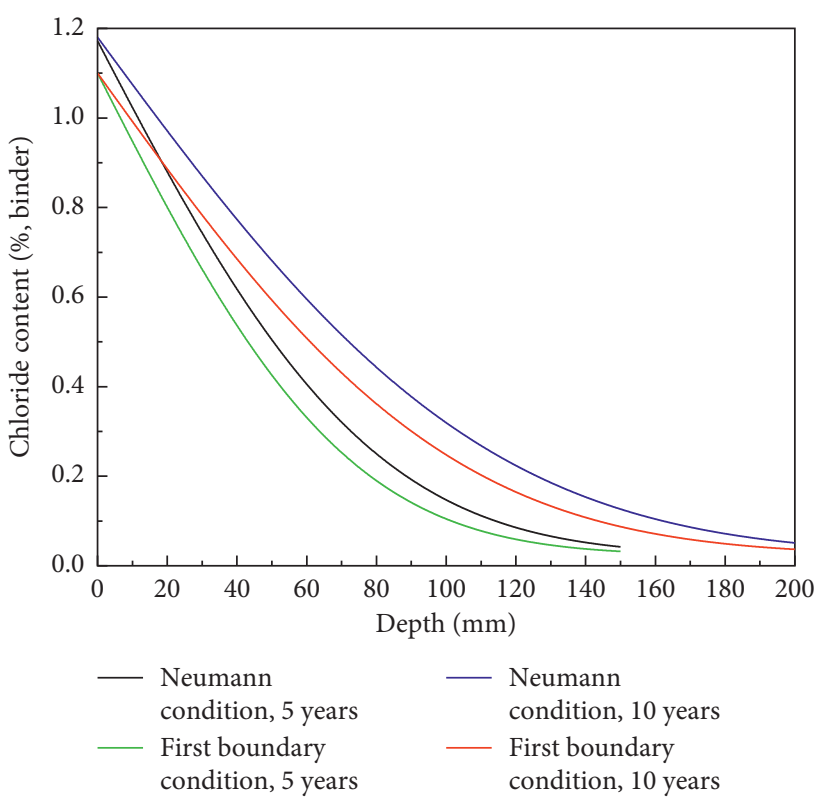

FIGURE 11: Long-term prediction at the age of 5 years and 10 years based on the tradition model and proposed model.

deduction. Laboratory tests were also conducted and good agreement was achieved.

(3) Compared with the traditional chloride transport model with the Dirichlet boundary condition, higher diffusion coefficient and surface chloride content are obtained by the Neumann boundary condition, which causes the penetration speed of chloride obtained from the proposed model with the Neumann boundary condition to be faster. Modeling of chloride distribution in cement-based materials with the Neumann boundary condition can solve the problems of durability being overestimated in longterm prediction.

(4) According to the experimental study based on different water-cement ratios, values of both $D_{\text {app }}$ and $C_{s}$ increase with the increase of water-cement ratio. However, the value of $d$ changes slightly with the water-cement ratio, and all values of $d$ fall in the range between $1.5 \mathrm{~mm}$ and $2 \mathrm{~mm}$.

(5) The present study performs the preliminary study on the Neumann boundary condition. The present study is based on the long-term curing, and the factor of curing age is not considered. Considering the curing age is an important factor for cementbased materials, it is necessary to further study the influence of curing age on chloride distribution with the Neumann boundary condition.

\section{Data Availability}

The experimental data used to support the findings of this study have been deposited in the Citrination repository (https:// doi.org/10.25504/FAIRsharing.x6y19r). The curve-fitting data 
used to support the findings of this study are included within the article.

\section{Conflicts of Interest}

The authors declare that they have no conflicts of interest.

\section{Acknowledgments}

This work was supported by the Fundamental Research Funds for the Central Universities (2018B17114), Natural Science Foundation of Jiangsu Province (BK20161507 and BK20150796), National Natural Science Foundation of China (51609075, 51608173, 51509081, and 51579088).

\section{References}

[1] L. Tang, "Concentration dependence of diffusion and migration of chloride ions: part 1. Theoretical considerations," Cement and Concrete Research, vol. 29, no. 9, pp. 1463-1468, 1999.

[2] T. Zhang and O. E. Gjørv, "Diffusion behavior of chloride ions in concrete," Cement and Concrete Research, vol. 26, no. 6, pp. 907-917, 1996.

[3] C. Andrade, M. Prieto, P. Tanner, F. Tavares, and R. D'Andrea, "Testing and modelling chloride penetration into concrete," Construction and Building Materials, vol. 39, pp. 9-18, 2013.

[4] M. Collepardi, A. Marcialis, and R. Turriziani, "Penetration of chloride ions into cement pastes and concretes," Journal of the American Ceramic Society, vol. 55, no. 10, pp. 534-535, 1972.

[5] U. Angst, B. Elsener, C. K. Larsen, and Ø. Vennesland, "Critical chloride content in reinforced concrete-a review," Cement and Concrete Research, vol. 39, no. 12, pp. 1122-1138, 2009.

[6] J. P. Hwang, M. S. Jung, M. Kim, and K. Y. Ann, "Corrosion risk of steel fibre in concrete," Construction and Building Materials, vol. 101, pp. 239-245, 2015.

[7] K. Y. Ann and H.-W. Song, "Chloride threshold level for corrosion of steel in concrete," Corrosion Science, vol. 49, no. 11, pp. 4113-4133, 2007.

[8] O. Poupard, A. Ait-Mokhtar, and P. Dumargue, "Corrosion by chlorides in reinforced concrete: determination of chloride concentration threshold by impedance spectroscopy," Cement and Concrete Research, vol. 34, no. 6, pp. 991-1000, 2004.

[9] A. Petcherdchoo, "Time dependent models of apparent diffusion coefficient and surface chloride for chloride transport in fly ash concrete," Construction and Building Materials, vol. 38, pp. 497-507, 2013.

[10] M. Glinicki, D. Jóźwiak-Niedźwiedzka, K. Gibas, and M. Dąbrowski, "Influence of blended cements with calcareous fly ash on chloride ion migration and carbonation resistance of concrete for durable structures," Materials, vol. 9, no. 1, p. 18, 2016.

[11] M. Marks, M. Glinicki, and K. Gibas, "Prediction of the chloride resistance of concrete modified with high calcium fly ash using machine learning," Materials, vol. 8, no. 12, pp. 8714-8727, 2015.

[12] S. Zofia and Z. Adam, "Theoretical model and experimental tests on chloride diffusion and migration processes in concrete," Procedia Engineering, vol. 57, pp. 1121-1130, 2013.
[13] T. El Maaddawy and K. Soudki, "A model for prediction of time from corrosion initiation to corrosion cracking," Cement and Concrete Composites, vol. 29, no. 3, pp. 168-175, 2007.

[14] S. Pack, M. Jung, H. Song, S. Kim, and K. Y. Ann, "Prediction of time dependent chloride transport in concrete structures exposed to a marine environment," Cement and Concrete Research, vol. 40, no. 2, pp. 302-312, 2010.

[15] B. Shafei, A. Alipour, and M. Shinozuka, "Prediction of corrosion initiation in reinforced concrete members subjected to environmental stressors: a finite-element framework," Cement and Concrete Research, vol. 42, no. 2, pp. 365-376, 2012.

[16] W. Fan and X. Wang, "Prediction of chloride penetration into hardening concrete," Advances in Materials Science and Engineering, vol. 2015, Article ID 616980, 8 pages, 2015.

[17] K. D. Stanish, "The migration of chloride ions in concrete," Ph.D. thesis, University of Toronto, Toronto, ON, Canada, 2002.

[18] B. K. Nyame and J. M. Illston, "Relationships between permeability and pore structure of hardened cement paste," Magazine of Concrete Research, vol. 33, no. 116, pp. 139-146, 1981.

[19] P. Halamickova and R. J. Detwiler, "Water permeability and chloride ion diffusion in portland cement mortars: relationship to sand content and critical pore diameter," Cement and Concrete Research, vol. 25, no. 4, pp. 790-802, 1995.

[20] M. Castellote, C. Andrade, and C. Alonso, "Measurement of the steady and non-steady-state chloride diffusion coefficients in a migration test by means of monitoring the conductivity in the anolyte chamber. Comparison with natural diffusion tests," Cement and Concrete Research, vol. 31, no. 10, pp. 1411-1420, 2001.

[21] X. Gang, L. Yun-pan, S. Yi-biao, and X. Ke, "Chloride ion transport mechanism in concrete due to wetting and drying cycles," Structural Concrete, vol. 16, no. 2, pp. 289-296, 2015.

[22] F. Tang, G. Chen, and R. K. Brow, "Chloride-induced corrosion mechanism and rate of enamel- and epoxy-coated deformed steel bars embedded in mortar," Cement and Concrete Research, vol. 82, pp. 58-73, 2016.

[23] B. Martín-Pérez, H. Zibara, R. D. Hooton, and M. Thomas, "A study of the effect of chloride binding on service life predictions," Cement and Concrete Research, vol. 30, no. 8, pp. 1215-1223, 2000.

[24] Q. Yuan, C. Shi, G. De Schutter, K. Audenaert, and D. Deng, "Chloride binding of cement-based materials subjected to external chloride environment-a review," Construction and Building Materials, vol. 23, no. 1, pp. 1-13, 2009.

[25] Q. Yuan, D. Deng, C. Shi, and G. De Schutter, "Chloride binding isotherm from migration and diffusion tests," Journal of Wuhan University of Technology-Materials Science Edition, vol. 28, no. 3, pp. 548-556, 2013.

[26] X. Lu, C. Li, and H. Zhang, "Relationship between the free and total chloride diffusivity in concrete," Cement and Concrete Research, vol. 32, no. 2, pp. 323-326, 2002.

[27] T. U. Mohammed and H. Hamada, "Relationship between free chloride and total chloride contents in concrete," Cement and Concrete Research, vol. 33, no. 9, pp. 1487-1490, 2003.

[28] P. Spiesz, M. M. Ballari, and H. J. H. Brouwers, "RCM: a new model accounting for the non-linear chloride binding isotherm and the non-equilibrium conditions between the freeand bound-chloride concentrations," Construction and Building Materials, vol. 27, no. 1, pp. 293-304, 2012.

[29] G. K. Glass, Y. Wang, and N. R. Buenfeld, "An investigation of experimental methods used to determine free and total 
chloride contents," Cement and Concrete Research, vol. 26, no. 9, pp. 1443-1449, 1996.

[30] C. Andrade, J. M. Díez, and C. Alonso, "Mathematical modeling of a concrete surface "skin effect" on diffusion in chloride contaminated media," Advanced Cement Based Materials, vol. 6, no. 2, pp. 39-44, 1997.

[31] K. Y. Ann, J. H. Ahn, and J. S. Ryou, "The importance of chloride content at the concrete surface in assessing the time to corrosion of steel in concrete structures," Construction and Building Materials, vol. 23, no. 1, pp. 239-245, 2009.

[32] J. Liu, K. Tang, D. Pan, Z. Lei, W. Wang, and F. Xing, "Surface chloride concentration of concrete under shallow immersion conditions," Materials, vol. 7, no. 9, pp. 6620-6631, 2014.

[33] A. Boddy, E. Bentz, M. D. A. Thomas, and R. D. Hooton, "An overview and sensitivity study of a multimechanistic chloride transport model," Cement and Concrete Research, vol. 29, no. 6, pp. 827-837, 1999.

[34] V. Elfmarkova, P. Spiesz, and H. J. H. Brouwers, "Determination of the chloride diffusion coefficient in blended cement mortars," Cement and Concrete Research, vol. 78, pp. 190-199, 2015.

[35] L. Tang, "Chloride transport in concrete-measurement and prediction," Ph.D. thesis, Chalmers University of Technology, Gothenburg, Sweden, 1996.

[36] B. Johannesson, K. Yamada, L. Nilsson, and Y. Hosokawa, "Multi-species ionic diffusion in concrete with account to interaction between ions in the pore solution and the cement hydrates," Materials and Structures, vol. 40, no. 7, pp. 651-665, 2007.

[37] B. H. Oh and S. Y. Jang, "Effects of material and environmental parameters on chloride penetration profiles in concrete structures," Cement and Concrete Research, vol. 37, no. 1, pp. 47-53, 2007.

[38] R. A. de Medeiros-Junior, M. G. de Lima, and M. H. F. de Medeiros, "Service life of concrete structures considering the effects of temperature and relative humidity on chloride transport," Environment, Development and Sustainability, vol. 17, no. 5, pp. 1103-1119, 2015.

[39] M. Hoseini, V. Bindiganavile, and N. Banthia, "The effect of mechanical stress on permeability of concrete: a review," Cement and Concrete Composites, vol. 31, no. 4, pp. 213-220, 2009.

[40] G. Li, F. Hu, and Y. Wu, "Chloride ion penetration in stressed concrete," Journal of Materials in Civil Engineering, vol. 23, no. 8, pp. 1145-1153, 2011.

[41] H. Wang, C. Lu, W. Jin, and Y. Bai, "Effect of external loads on chloride transport in concrete," Journal of Materials in Civil Engineering, vol. 23, no. 7, pp. 1043-1049, 2011.

[42] H. Song, C. Lee, and K. Y. Ann, "Factors influencing chloride transport in concrete structures exposed to marine environments," Cement and Concrete Composites, vol. 30, no. 2, pp. 113-121, 2008.

[43] C. Andrade, M. Castellote, and R. D’Andrea, "Measurement of ageing effect on chloride diffusion coefficients in cementitious matrices," Journal of Nuclear Materials, vol. 412, no. 1, pp. 209-216, 2011.

[44] Y. Sun, M. Liang, and T. Chang, "Time/depth dependent diffusion and chemical reaction model of chloride transportation in concrete," Applied Mathematical Modelling, vol. 36, no. 3, pp. 1114-1122, 2012.

[45] G. De Schutter, "Finite element simulation of thermal cracking in massive hardening concrete elements using degree of hydration based material laws," Computers \& Structures, vol. 80, no. 27-30, pp. 2035-2042, 2002.
[46] Y. Ballim, "A numerical model and associated calorimeter for predicting temperature profiles in mass concrete," Cement and Concrete Composites, vol. 26, no. 6, pp. 695-703, 2004.

[47] J. Crank, The Mathematic of Diffusion, Clarendon Press, Oxford, UK, 1983. 


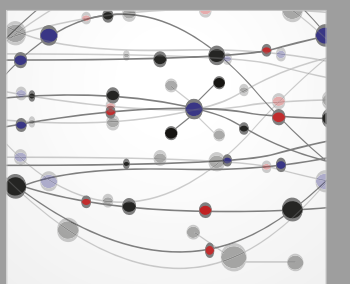

The Scientific World Journal
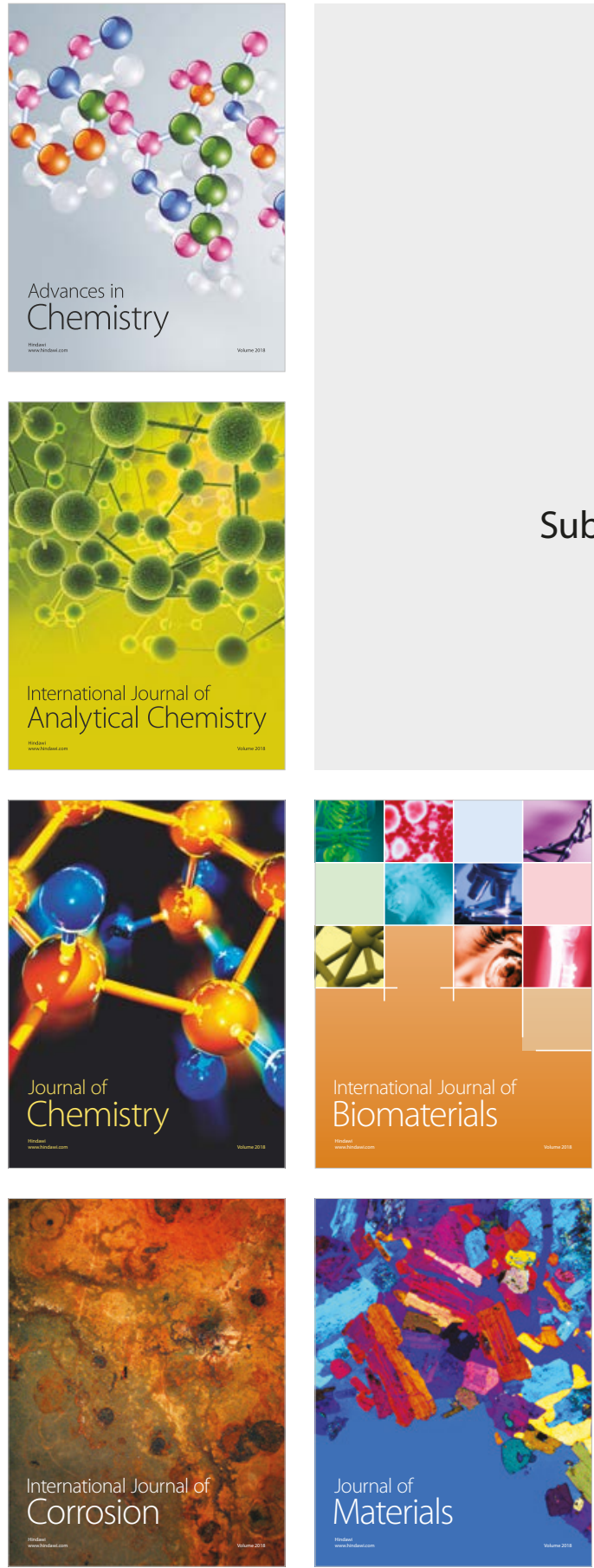

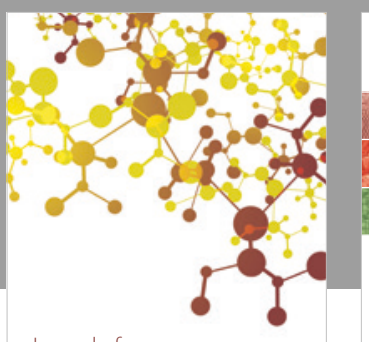

Journal of

Applied Chemistry
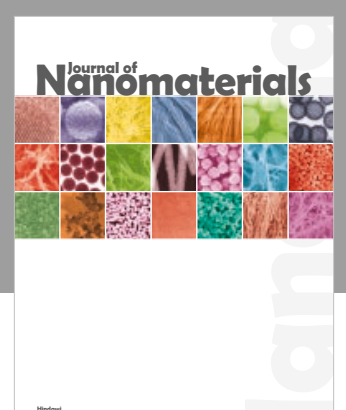

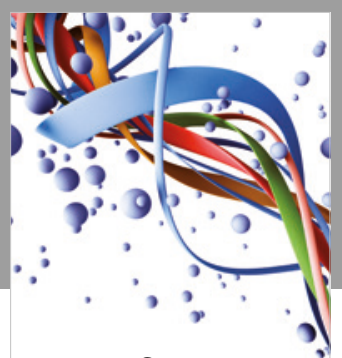

Scientifica

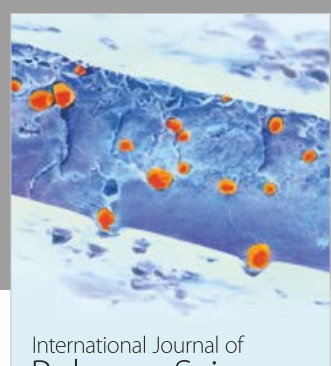

Polymer Science

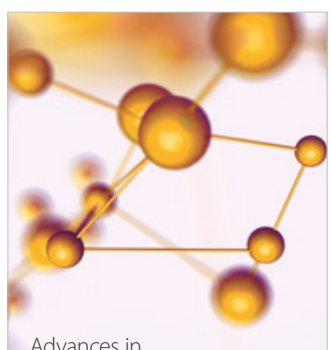

Physical Chemistry
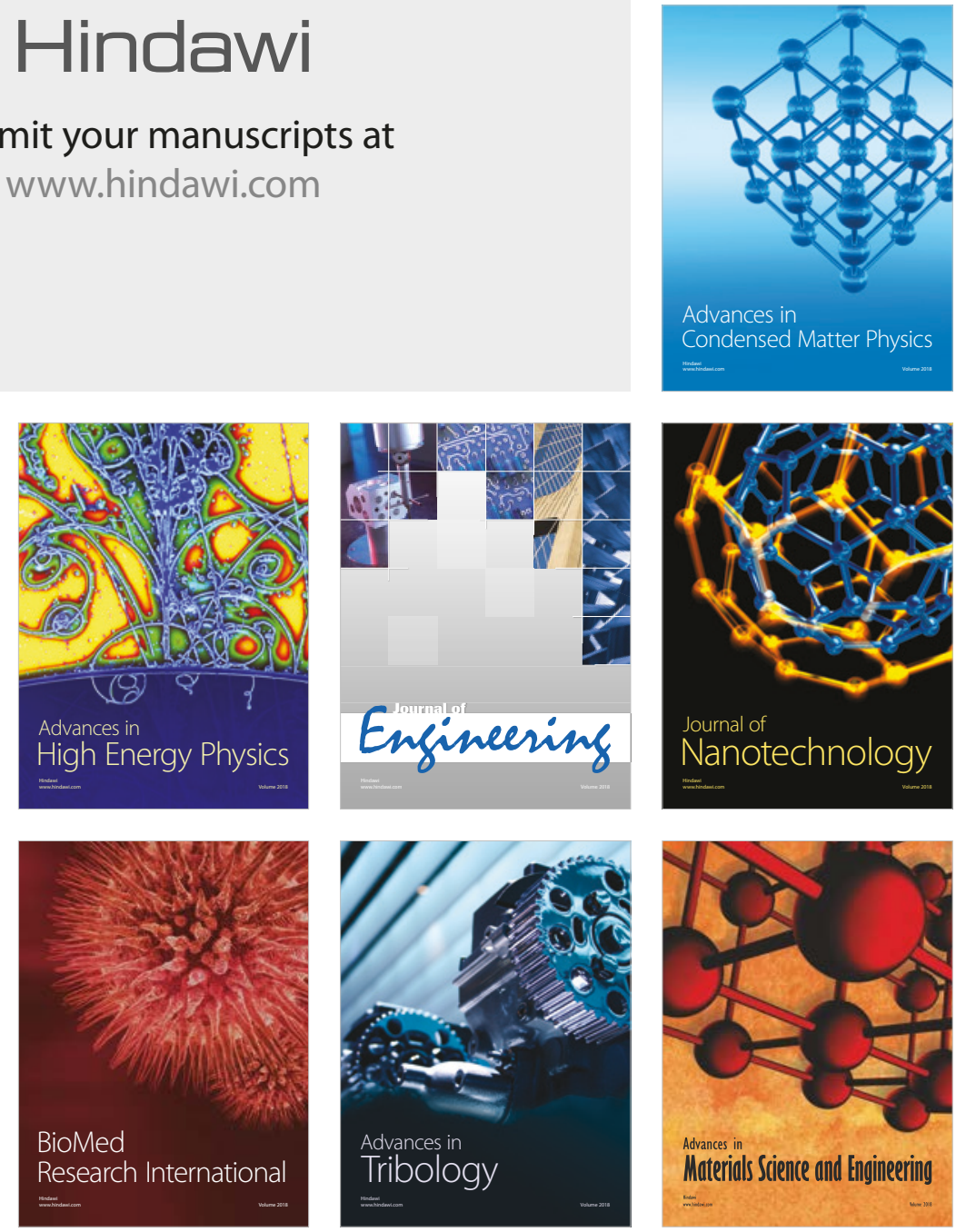